\title{
ForestSim Model of Impacts of Smallholder Dynamics: Forested Landscapes of the Upper Peninsula of Michigan
}

\author{
Audrey L. Mayer ${ }^{1,2}$ and Mark D. Rouleau ${ }^{2}$ \\ ${ }^{1}$ Department of Social Sciences, Michigan Technological University, 1400 Townsend Drive, Houghton, MI 49931, USA \\ ${ }^{2}$ School of Forest Resources and Environmental Science, Michigan Technological University, 1400 Townsend Drive, \\ Houghton, MI 49931, USA
}

Correspondence should be addressed to Audrey L. Mayer; almayer@mtu.edu

Received 21 March 2013; Accepted 9 May 2013

Academic Editor: Piermaria Corona

Copyright (c) 2013 A. L. Mayer and M. D. Rouleau. This is an open access article distributed under the Creative Commons Attribution License, which permits unrestricted use, distribution, and reproduction in any medium, provided the original work is properly cited.

\begin{abstract}
Many forested landscapes in the United States contain a large number of small private landowners (smallholders). The individual decisions of these smallholders can collectively have a large impact on the structure, composition, and connectivity of forests. While models have been developed to try to understand this large-scale collective impact, few models have incorporated extensive information from individual decision-making. Here we introduce an agent-based model, infused with sociological data from smallholders, overlaid on a GIS layer to represent individual smallholders, and used to simulate the impact of thousands of harvesting decisions. Our preliminary results suggest that certain smallholder characteristics (such as relative smallholder age and education level as well as whether a smallholder is resident or absentee) and information flow among owners can radically impact forests at the landscape scale. While still in its preliminary stages, this modeling approach is likely to demonstrate in detail the consequences of decision-making due to changing smallholder demographics or new policies and programs. This approach can help estimate the effectiveness of programs based on landscape-scale programmatic goals and the impact of new policy initiatives.
\end{abstract}

\section{Introduction}

A critical dimension of sustainable natural resource management centers upon the relationship between human land use and land cover change [1]. Sustainability and sustainable resource management incorporate the impacts of activities on environmental, social, and economic conditions from the local to global scale, with the target of a level of use that can be maintained indefinitely without reducing the productivity of other areas or systems [2]. Sustainable forest management has chiefly been defined by organizations such as the FAO and standards systems such as the Forest Stewardship Council, although these certifications are often focused on environmental issues and few have indicators that identify or delineate landscape-scale sustainability $[3,4]$. For the purposes of this paper, we will identify sustainable forest management at the landscape scale as actions that result in large patches of mature forest along with moderate levels of heterogeneity in forest patch size and stand age. Functioning ecosystems of significant size are better able to provide ecological goods and services and sustain the productivity of forestry and other resource-intensive industries at the landscape scale [5-8].

Land managers directly influence land use and land cover dynamics, and managers differ in favoring some land cover types over others, thereby influencing the patterns and diversity of land cover types $[9,10]$. Their cumulative decisions determine whether natural resources are used sustainably or whether these resources are likely to be severely degraded; apart from the largest of land managers, individuals rarely have the power to preserve their own resources in the presence of large-scale unsustainable resource use [1]. In this way, the aggregate impact of many smallholder natural resource management decisions can have a massive effect on landscapes-Odum's "tyranny of small decisions" [11-15] (we use the term "smallholder" here to refer to individuals or 
family units that make land use decisions on small allotments, leased areas, or privately-held properties). Although land use regulations and incentive policies are meant to coordinate land use at larger scales, small landowners in the United States do not enthusiastically embrace these coordinating efforts $[15,16]$. To develop and implement programs for natural resource use that local and/or regional communities are more likely to embrace, it is necessary that we understand how and why these countless land use decisions are made in response to factors at multiple scales $[17,18]$. Fortunately for policy development purposes, the dynamics of these many small decisions often exhibit patterns due to self-organized behaviors that converge on one of several possible outcomes given a diverse, but known, set of smallholder characteristics and interactions with each other and with the environment $[17,19$, 20]. Once the interactions among smallholders and drivers of these patterns are identified, policies can be specifically targeted to enhance positive behaviors (or dissuade negative ones). Agent-based models can then be used for hypothesis testing purposes, running multiple simulation iterations under different parameter settings and comparing the results to real-world observations, as a way to demonstrate how (and to what extent) the identified local drivers produce large-scale landscape features through interactions among smallholders and the natural environment.

\section{Background}

Natural resource management studies have increasingly adopted computational modeling as a way to better understand ecosystem complexity and coupled socioecological systems [21, 22]. Although management goals vary across studies, much of this work uses computational modeling to generate "futures scenarios" for resource managers curious about the possible intended and unintended consequences of a given land management strategy (e.g., [6, 23-27]). Of course, these futures scenarios do not (or cannot) predict the exact future state of a given ecosystem-system complexity makes this impossible. Rather, futures scenarios provide a confidence window of the probable states a given ecosystem is expected to traverse through time. The quality (or reliability) of these scenarios is highly contingent upon a given model's ability to adequately capture the complex mechanisms driving ecosystem dynamics. Many of these models rely on top-down (i.e., centrally controlled) designs that require researchers to aggregate and homogenize the socio-ecological complexity driving these systems. Bottomup (i.e., agent-based) methods might alleviate this source of potential error and allow for stakeholders to help design the model to better meet their needs and goals [28].

Early natural resource models often used single species (or resource) deterministic models to identify sustainable resource use with no interaction among environmental or human components [22]. In time, models became more sophisticated and incorporated interactions among environmental components, with some interaction with land and resource managers and a spatial dimension, but still aggregated [29-31]. In these models, subsystems (e.g., the natural system, the social system, the economic system, etc.) are often modeled as stocks, and interactions among subsystems are modeled as flows (i.e., the rates of change in one subsystem are a function of the level of interaction with other subsystems). Aggregate models of this type can successfully replicate some important general dynamics inherent in ecosystem interactions, such as the interdependent and nonlinear levels of phosphorus in the water and land use. However, aggregate models must make a number of oversimplified assumptions that can lead to management surprises when interactions and feedbacks at multiple scales drive the system into a new state not identified by the model [32].

The major drawback to aggregate modeling is its lack of individual-level heterogeneity. In other words, one must assume some homogeneity within populations or environmental components. Aggregate models can introduce a stochastic element to account for the variance of these individualized differences (e.g., [33]), but this approach simply masks the underlying micro-level drivers of systemic change, making it impossible to isolate which of these factors are responsible for macrolevel complexity. Even though some of these models do incorporate a spatial dimension, it is impossible to understand the macrolevel spatial consequences of lower-scale interactions on a particular landscape. Examples of aggregated models for land use and management include Hartter and Boston's [34] model of land conversion to agriculture based on the caloric needs of households and Brown et al.s [35] model of land use change in the Upper Midwest region of the United States. Such models, focusing on the ecological impacts of harvesting and land use conversion, often simulate land use decision-making as a probability of land use transition based on observed transition rates without incorporating the social mechanisms underlying these transition decisions (e.g., [35-39]). Consequently, while forest ecosystem characteristics are disaggregated within these models, ownership decision-making is still aggregated by owner class (e.g., public, industrial, smallholder) and therefore is relatively homogenous within class.

Recognition of the limitations of aggregate modeling has led many researchers to gravitate towards agent-based modeling (ABM), also called individual-based modeling ((IBM) $[21,22])$. In some ways, ABM makes the opposite assumption about parsimony as aggregate modeling. Rather than representing the system as a set of aggregate and abstract interacting subcomponents, ABMs model the individual interacting actors or "agents" and their direct relations with the environment. To do this, modelers create agents with the minimum decision-making and behavioral complexity necessary to replicate complex system level phenomenon. These agents then interact in an artificial environment, which is often a cellular automata or GIS-based rendering of a natural system (e.g., [26]). Through the course of an ABM simulation, interactions among diverse agents, following relatively simple rules of behavior, typically produce complex emergent phenomenon over time. Emergence in this case refers to the appearance of systemic features that are more complex than the individual interactions responsible for their creation. The advantage of the ABM approach is that it allows modelers to replicate the heterogeneity of agents and agent 
interactions as well as to adequately represent the spatial implications of these interactions [40].

ABMs have been used for decades to understand complex ecological communities and ecosystems [12, 17, 19]. They have been particularly useful for systems in which many organisms have a very large influence on other organisms in their immediate surroundings but a much smaller impact (as individuals) on the entire system [41-43]. Early efforts used cellular automata models to simulate processes such as the dispersal of organisms to patches of preferred habitats [44]. These cellular automata models are basically grids of autonomous interacting cells with each cell representing an explicit spatial location or "patch" and the state of a given cell being dependent on the state of its neighboring cells. For example, in the Hill and Caswell [44] model, each grid cell represents either an occupied or unoccupied patch, and the state of each cell is dependent upon the level of species occupation within a patch at a given point in time. Over time, the flow of species from one patch to the next responds to the relative states of neighboring patches (species either become extinct due to overcrowding or migrate to neighboring unoccupied patches if possible). This cellular automata approach clearly allows for the investigation of greater degrees of spatial complexity, such as the fragmentation of occupied patches as a consequence of the dispersal of species throughout a landscape. However, aggregation is still a concern for these early cellular automata models because they often lack an explicit representation of agency. Aggregation occurs because all cells are homogeneous in their deterministic response (from one state to another); cells lack agency. This is particularly problematic for modeling ecosystem dynamics driven by autonomous decision makers such as humans, whose heterogeneous land use activities can significantly impact ecosystem dynamics.

Agent-based models can incorporate a great deal of individual-level decision-making complexity. Early models examined intra- and interspecies competition and food web dynamics (e.g., [41, 45]) and interacting trophic and abiotic layers operating at multiple scales (e.g., the Across Trophic Level System Simulation model for the Florida Everglades [46] and the LUCITA model for the Brazilian Amazon $[14,47])$. These models demonstrated that feedbacks and interactions within and among components result in a great deal of complex behavior, both spatially and temporally [17, 42]. ABM uses have now proliferated, and quite a few have been developed to investigate linkages between smallholder behavior and land use change (e.g., [13, 48-51]). However, in order for agent-based models to be useful to decision makers, the agents must accurately represent a realistically diverse suite of human behaviors and decision-making processes within a system or landscape. This is only possible through the combination of agent-based models with extensive behavioral data collected from robust sociological studies [52], or using a participatory model development approach (e.g., [51]). Top-down or other equation-based models where all human behaviors are aggregated into one component (e.g., [35]) may not capture the heterogeneity of possible agent decisions and can lead to simulation results that differ from those generated from agent-based models [52].
Here we describe a computational approach to understand complex forest ecosystems and their underlying nonlinear dynamics. We outline the emerging use of computational models to explore complex social-environmental problems, particularly those involving land management. We also identify the potential advantages of these approaches and highlight known limitations. We argue that one of the key limitations to prior computational work has been an overreliance on aggregate or top-down modeling. This topdown approach greatly oversimplifies interactions between ecological and social dynamics. Such models therefore fail to properly account for "emergent" phenomenon. Consequently, bottom-up, individualistic approaches to land use/land cover modeling have emerged to address these limitations. We present our bottom-up computational approach using an agent-based model (ABM) and smallholder interviews, to replicate the complex feedbacks in a linked socialenvironmental system. We demonstrate that this approach produces more realistic land cover patterns and, as a result, can more accurately assess ecosystem sustainability.

\section{Methods}

3.1. Study Area. The study area for our model is the Western Upper Peninsula of Michigan. The land area includes approximately $23,000 \mathrm{~km}^{2}$, with an average population density of 7.5 people per $\mathrm{km}^{2}$ (according to the 2010 US Census Bureau survey). The land cover is $80 \%$ forest, mainly a mixture of northern hardwoods and coniferous forest types. Prior to large-scale intensive logging beginning in the 1860s, the forests of the Western Upper Peninsula (WUP) were dominated by white pine (Pinus strobus), sugar maple (Acer saccharum), eastern hemlock (Tsuga canadensis), and yellow birch (Betula alleghaniensis) [53]. The 1842 Treaty of La Pointe (7 Stat. 591) between the federal government and local Ojibwe tribes transferred most of the land to government ownership. The government then sold or leased the land to large timber industries or small nonindustrial landowners for harvesting or agricultural production. In the 1920s, after most of the area had been harvested, the government converted its remaining holdings (about $30 \%$ of the WUP) to federal and state forests (e.g., Ottawa National Forest, Hiawatha National Forest). The remaining $70 \%$ of land is evenly split between large industrial (or corporate) owners and small, nonindustrial private owners. The WUP encompasses 8 counties: Baraga, Dickinson, Gogebic, Houghton, Iron, Keweenaw, Marquette, and Ontonagon.

For this model, we focused on Houghton County; at present about $80 \%$ of Houghton County is forested, primarily with upland hardwoods (e.g., sugar maple, yellow birch (Betula alleghaniensis), American beech (Fagus grandifolia), and basswood (Tilia americana)) [54]. The Ottawa National Forest covers $23 \%$ of the southern part of the county, and overall about $30 \%$ of the county is owned by the public. Industrial ownership covers about $35 \%$ of the area, and nonindustrial smallholders own $30 \%$. Several large timber investment management organizations and real estate investment trusts now own what was originally timberland 
owned by private timber companies [55]. These industrial and investment owners are likely to parcelize their holdings, particularly around lakes (for summer cottages) and along roadways (for residential development) [56]. Although there has been some aggregation of parcels, the trend is towards more divisions of properties and therefore an increasing total number of smallholders. The shift from an economy based on forest products to more recreation and tourism has allowed the forests to rebound from the severe deforestation event in the late 1800s and early 1900s, leading to a sustained trend in increased forest cover that continues today [57].

3.2. Information from Literature Review and NWOS. We collected information on likely behaviors and decisionmaking based on landowner characteristics (e.g., age, income, education, residency, and land tenure) of nonindustrial forest owners in the United States (and for Michigan when the information was available), which then translated into agent attributes in the model; the diversity of these attributes increased the heterogeneity in the model [52]. The sources of these data included the National Woodland Owner Survey ((NWOS) http://www.fia.fs.fed.us/nwos/ [58]) and an extensive literature review of private forest owners in North America and Europe (see the References sections of 59-60 for a list of all sources used). Briefly, these surveys and studies have found that older smallholders are more likely to manage and harvest their forests and are more likely to live on or very close to their forest holdings. Alternatively, younger owners (and those who inherit their forest) are more likely to live farther away and less likely to actively manage their forests or have a management plan. Although older owners are more likely to harvest, they are more likely to use selective cutting, while younger owners are more likely to clear-cut. Forest owners with more education are more likely to manage their forests, and slightly more likely to harvest them (particularly selective harvests). Finally, absentee smallholders are more likely to clear-cut than resident smallholders.

3.3. Information from Landowner Interviews. Underpinning agent behavior with real-world observed or surveyed behavior is critical to ensuring that the model generates realistic scenarios [52]. In 2011 we conducted 34 telephone interviews with smallholders in the Western Upper Peninsula, specifically to determine from which sources they received forest management information [59]. Interviewees were chosen using a random selection of forest owners and then a snowball method (i.e., interviewees suggested other forest owners they knew for potential interviews, typically those owners from whom they received management advice). A list of questions and detailed information on the interview methodology is available from [59]. From these interviews we gained a preliminary sense of the social structure of the smallholder community with respect to information flow. We determined that a majority of smallholders received management information from their neighbors, either directly through discussions with them or indirectly through observations of management activities on adjacent properties. We incorporated this information in our model through the stronger harmonization of harvesting activity with proximity (i.e., harvested or not, selective cut or clear-cut). However, we prevented absentee smallholders from coordinating harvests with neighbors to reflect a much lower level of information flow between absentee and resident smallholders [59].

3.4. Model Development. Agent-based modeling (ABM) is a useful tool to formally replicate the dynamics of a Complex Adaptive System (CAS) [60]. ABM can be used to identify the underlying micro-level mechanisms necessary to replicate (and explain) complex macro-level phenomena. ABMs are particularly well suited to replicate the novel characteristics of a CAS that we see present in our study area. As with a CAS, an ABM is a computer simulation designed specifically to replicate the interactions of any number of autonomous agents with themselves and with their environment. It is difficult-if not impossible - to formally reproduce the complex phenomena of a CAS without the ABM approach [61]. In fact, the ability to investigate the nonequilibrium dynamics responsible for most complex emergent phenomenon is the most important strength of an ABM, as compared to other formal methods [62]. In addition, ABM provides a valuable tool to not only learn from the past but also look to the future. ABM simulations are often used to experiment with futures scenarios. Once a model is capable of replicating current conditions, it is then possible to manipulate the model parameters to explore how isolated changes lead to future consequences. These "in silico" experiments allow researchers to test the implications of countless policy prescriptions without risk to stakeholders and without having to wait for the actual policy consequences to play themselves out in the real world [63]. Thus, policy makers can run their policy prescriptions in the model before taking them to the field. Our long-term research goal is to develop an ABM simulation of smallholder land use management capable of forecasting land use changes as a consequence of changes in land management policies. The model presented below provides the foundational framework necessary to accomplish this goal. We show in this paper that our model is capable of passing key validity tests which we believe are necessary to accomplish before introducing further modeling complexity (we discuss opportunities for future work in our Conclusion section).

Below we describe our model in terms of the overview, design concepts, and details (ODD) protocol advocated by Grimm et al. [64].

3.4.1. Purpose. Our smallholder forester agent-based model (ForestSim) is written in the Java programming language, using the MASON simulation library and the GeoMASON Geographic Information Systems (GIS) visualization and analysis package $[65,66]$. MASON is a discrete-event agentbased simulation library for the Java programming language designed as a platform-independent toolkit used to develop custom-built agent-based simulations. MASON provides a wide range of basic simulation tools including an agent scheduler, a graphical user-interface, a suite of lightweight 
data analysis features, and a simulation core. The objectoriented character of Java, which underpins all MASON simulations, is best suited to generate the bottom-up emergence we seek to model. The purpose of ForestSim is to simulate the socioecological dynamics of smallholder land use decision-making, with a primary focus on the social influence dimension of natural resource management. To do this, we simulate the agent-level flow of management information amongst diverse smallholders to explore how social influence impacts forest sustainability at the forest landscape scale. We use GIS shapefiles to situate our smallholder agents within real forest landscapes, with decisionmaking by agents dependent upon survey and interview data. Our model endeavors to demonstrate the importance of social influence to replicate known macrolevel land cover complexities, such as the clustering of forest management practices and their concurrent land cover changes within a given landscape.

3.4.2. Entities, State Variables, and Scales. The ForestSim model has two main components: the forest landscape (the agent environment) and the smallholder agents who interact within this landscape. ForestSim was designed to use GIS shapefile layers to represent the agent environment. In fact, it is possible to import any GIS shapefile layer into ForestSim for the purposes of experimentation, but shapefiles with extremely large numbers of smallholder properties significantly increase the execution time of each model run. Thus, for the purposes of this paper, we have chosen to demonstrate ForestSim using the ESRI shapefile layer for the 2010 US census blocks in Houghton County. With this in mind, it is important to note that the census blocks in this case serve as quasiproperty boundaries. Due to the large number of properties at the county level, parcel boundary layers would require simulations to be broken down into smaller landscapes and, thus, make it difficult to visualize the land cover change impact on large-scale landscapes. Census blocks also provide information on median age, education, and other agent characteristics that are relevant to this study. With the property boundaries set to census blocks, each parcel is then initialized with the maximum forest cover value with a continuous range between clear-cut and old growth $(0.0$ to 1.0). This forest cover value is then updated during each round to account for forest growth and recent land use activities on a given parcel. The forest cover of the current parcel as well as the forest cover of neighboring parcels (neighbors are parcels who share a property boundary) determines the local forest regrowth rate (we consider only natural regeneration here, not planting). As a consequence, land use changes to neighboring parcels impact not only the current parcel but also neighboring parcels through this regrowth function.

The agents of ForestSim represent individual smallholders. Smallholder agents also possess the following attributes: age, education (low to high, where low is a maximum of a high school diploma and high is a Bachelor's degree or higher), association membership (yes or no), residence status (fulltime resident or part-time resident), and inheritance status (inherited property or not). While gender is a very influential characteristic of land management decision-making, gender is rarely studied explicitly [67]. At this time, we do not have adequate data to code decision rules for gender, but we are pursuing data to hopefully include it in further versions. The initial smallholder characteristics are randomly assigned to agents using a weighted random draw that varies from one experiment to the next (see the initial conditions of each experiment below). These specific smallholder attributes were identified by surveys and interviews as the most significant factors to impact land use decision-making with respect to forest management practices (see Sections 3.2 and 3.3). In each round, smallholder agents use a weighted probability to determine which of three possible land use activities they will execute: no action, selective cutting, or clearcutting. In this version of the model, each smallholder only owns one property; later versions can link properties owned by one smallholder so that land management can be coordinated across properties. The likelihood of taking any harvest action versus no action is the same for all smallholder agents. However, younger agents, agents with a low education, or agents who have inherited their property are more likely to clear-cut rather than selectively harvest (and vice versa). Furthermore, agents who possess more than one of these characteristics are both more likely to harvest and more likely to clear-cut. Finally, smallholder agents also possess links to neighboring parcels and social network links to all agents in the global smallholder land association. This allows smallholder agents to determine the locally (nearest neighbors only) or globally (association members across the landscape) "popular" land use activity. In simulations with social influence, smallholder agents are more likely to adopt this popular land use activity as opposed to their more typical land use choice.

3.4.3. Process Overview and Scheduling. ForestSim utilizes the MASON simulation scheduler to execute a simulation run. The MASON scheduler uses a priority queue to schedule agents for action. Parcel agents are given the highest priority in this queue followed by the smallholder agents. Thus, at the beginning of each round, all parcel agents update their current land cover prior to smallholder action. Once the land cover of each parcel is updated, smallholder agents are then randomly scheduled to act. Each smallholder agent first updates its age by one year. The smallholder agent is then given the opportunity to choose a land use activity for that round. Once selected by the scheduler, the chosen smallholder agent selects a land use activity to execute (see above) and is then returned to the end of the queue. After the scheduler has scheduled each agent for action, the round ends, and the smallholder queue is rerandomized for the next round. Each round of ForestSim represents one year.

The typical simulation loop for each land use experiment went as follows. First, the agents and agent environment were initialized. Each agent was assigned one parcel for all parcels within Houghton County. Agents were then randomly assigned demographic characteristics based on the experimental parameters (see below). Finally, the forest cover of all parcels was initially set to "old growth" 
(the maximum growth value of 1.0). Once the model was initialized, simulations were run for 100 rounds with each round representing a single year. During each round, agents would determine whether to clear-cut, selectively harvest, or do nothing. This decision was based upon a weighted probability, which itself was determined by the agent's current demographic characteristics, ownership objectives, and the actions of neighboring agents. For example, an agent was more likely to clear-cut if its current age was below 50, its current resident status was absentee (the other status being permanent resident), its ownership objective was to maximize income (the other objectives being aesthetics and recreation), its other neighbors were harvesting, and so on. Finally, the probability of ownership turnover would progressively increase as agents approached 100 years old allowing us to capture certain ownership turnover dynamics such as when young smallholders inherit or purchase the parcels older agents previously owned. Once an agent reaches 100 years old, the parcel is automatically turned over to a younger agent. For each simulation run of 100 rounds, the simulation has included the dynamics for four generations of people and one generation of trees. Despite this seemingly simple model structure, repeating this process for all agents over 100 rounds resulted in complex land use patterns. Furthermore, the flexibility of this model design allowed us to adjust our full set of initialization parameters at the start of the simulation or in real-time to explore a wide range of landscape scenarios such as the impacts of high versus low absenteeism or young versus old populations. We were also able to replicate the clustering of management outcomes ignored by most aggregate land use models.

3.4.4. Design Concepts. ForestSim draws on Social Impact theory to explain why land use and land cover change typically follow a clustered patterned throughout a given landscape. Social Impact theory suggests and our interviews with smallholders confirm that the social influence plays an equal and often a more important role in shaping land use decisions when compared to economic factors such as the going timber rate or the recreational preference of the individual smallholder. This is particularly true for distinguishing selective harvesters, from clear-cut harvesters but social influence or lack thereof can also significantly impact inaction.

We use ForestSim to model social influence in three ways. First, each smallholder agent is capable of observing local land use activities prior to making a land use decision. In other words, smallholder agents observe their neighbor's land use activities and are "pressured" to adopt the popular method of land management as determined locally. "Pressure" in this case means that the weighted probability of land use decision-making is weighted more heavily towards the locally popular land use activity. Second, some smallholder agents are also members of land owner associations and, thus, are pressured to adopt the "suggested" land use activity as defined by the majority land use practice within the collectivity of smallholder association members. Finally, we also include absentee smallholders in the landscape who determine their land use decisions entirely absent of social influence, using the traditional land use factors of age, education, and inheritance. This threefold approach to social influence results in an emergent pattern of land cover change clustering within our simulation. Furthermore, it is possible to modify the social and life history parameters used for agent decision-making prior to each simulation run in order to assess the relative impact of each parameter on the overall clustering of land change within the forest landscape. The results we present in the next section focus specifically on the impacts of various parameter changes with respect to the emergence of land cover change patterns.

\section{Results and Discussion}

To explore the impacts of smallholder characteristics and social influence on land management with respect to the sustainability of forest landscapes, we performed a number of simulation experiments using the ForestSim model. Each simulation experiment was repeated 500 times for each experiment (in other words, 500 runs for each possible combination of parameters). The results presented below are averages from the 500 simulation runs for each experiment using the same parameter settings. Every difference in means for each experimental result was found to be statistically significant at the $99 \%$ confidence level ( $P$ value $>0.01$ ). We present results from five experiments and discuss the impacts on forest age and land cover clustering within the forest landscape. The goal of these simulation experiments is to demonstrate how the microlevel mechanisms of land use decision-making identified above contribute to the emergence of macrolevel landscape features. In this section, we adopt the mantra of the agent-based modeling community, which says, "if you can grow it, you can explain [63]." In this respect, we validate our qualitative claims by showing that such relatively simple micromechanisms can in fact produce the complex macrolevel landscape patterns found in reality.

4.1. Smallholder Age and Forest Age. Our first experiment assessed the impact of increasing the proportion of young smallholders within the landscape. For this experiment we held all other variables constant while varying the likelihood that a given smallholder's age (assigned at the start of the simulation or after the death of a smallholder) would be less than 50 years old. This allowed us to test the impact of a youthful population on the mean forest age. Our results show that increasing the proportion of young smallholders within the landscape significantly decreased the average age of the forest (see Figure 1). This result is expected because we know that, if a smallholder has decided to take a land use action, younger smallholders are more likely to clear-cut their lands rather than to selectively cut. Therefore, smallholder age has both a local- and a landscape-level impact. At the local level, the average forest age for individual parcels is lower due to the greater likelihood of clear cutting with a more youthful population, but, at the landscape level, more clearcutting also results in a slower recovery rate for surrounding parcels in 
that clusters of clear-cut forest regrow slower than selective cut, old growth, or mixed clusters.

4.2. Smallholder Inheritance and Forest Age. Our second experiment assessed the impact of increasing levels of inheritance within the landscape. For this experiment we held all other variables constant while varying the likelihood that a given smallholder would inherit their property. This allowed us to test the impact of intergenerational effects on the mean forest age. As we expected, increasing the likelihood a smallholder would inherit their property also significantly decreased the average age of the forest within the landscape (see Figure 2). Smallholders who inherit their property are more likely to clear-cut their lands as opposed to selective cutting. Once again, this has both a local-and a landscapelevel impact, as was true for smallholder age.

4.3. Smallholder Education Level and Forest Age. Our third experiment assessed the impact of decreasing the overall level of education within the landscape. For this experiment we held all other variables constant while varying the education level of the smallholders. This allowed us to test the impact of education on the mean forest age. As expected, increasing the proportion of low educated smallholders also significantly decreased the average age of the forest within the landscape (see Figure 3). The lower the level of education a smallholder has, the more likely they are to clear cut their land as opposed to selective cutting. Once again, this has both a local and a landscape-level impact, as was also the case with smallholder age and inheritance.

4.4. Smallholder Age, Inheritance, Education, and Forest Age. Our fourth experiment assessed the combined impact of age, inheritance, and education within the landscape. For this experiment we held all other variables constant while simultaneously varying (in the same direction) the smallholder age, education, and inheritance levels. This allowed us to test the combined impact of a young population with a low education who mostly inherited their lands on the mean forest age. As we expected, landscapes with high levels of all three of these characteristics resulted in a significantly lower mean forest age than landscapes with lower levels of these three characteristics (see Figure 4). This result is expected because of what we know about smallholder age, inheritance, and education level in the previous three experiments. At this point, ForestSim has demonstrated its ability to adequately simulate both the isolated and combined effects of smallholder age, education, and inheritance on the average forest age at the landscape level. In this sense, ForestSim can be relied upon to replicate the impacts of smallholder characteristics on average forest age in the same way as the typical aggregate model.

4.5. Social Influence, Land Use/Land Cover Change Clustering, and Forest Age. The next experiment shows how ForestSim goes beyond aggregate models to include the social influence dynamics needed to produce spatial clustering. This experiment assessed the impact of social influence on land use and land cover clustering and the average forest age within the

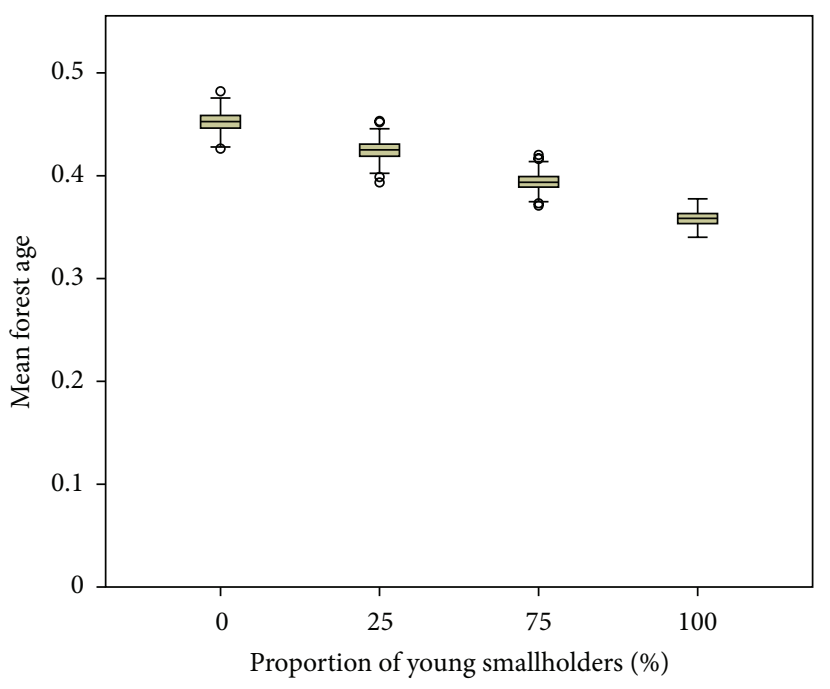

FIGURE 1: Mean forest age (at the landscape scale) increases significantly as the proportion of young smallholders decreases.

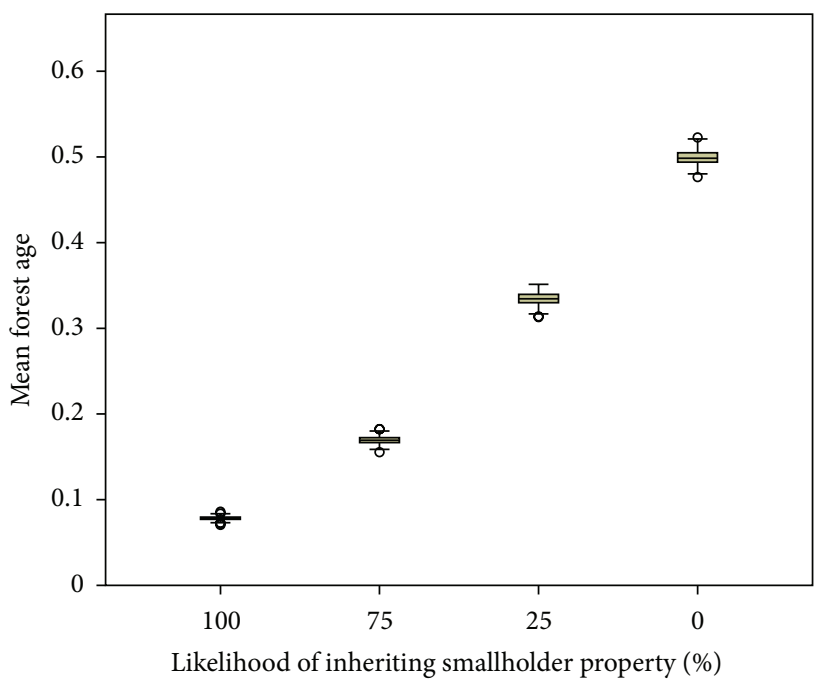

FIGURE 2: Mean forest age (at the landscape scale) increases significantly with decreasing likelihood of inheriting one's smallholder property.

landscape. For this experiment we held all other variables constant (with absenteeism set to $10 \%$ ) while simultaneously varying the likelihood a smallholder agent would adopt the most popular land use practice of its nearest neighbors (parcels must share a border to be considered neighbors). This allowed us to test the impact of social influence on both land cover change clustering and mean forest age throughout the landscape. The results from this experiment showed that greater levels of social influence led to increased land use and cover change clustering (see Figure 5) as well as an increase in the average forest age (see Figure 6). Without social influence, ForestSim is comparable to aggregate models in that it accurately generates the expected asocial relationships between smallholder characteristics and average forest age within the landscape. However, the addition of social influence 


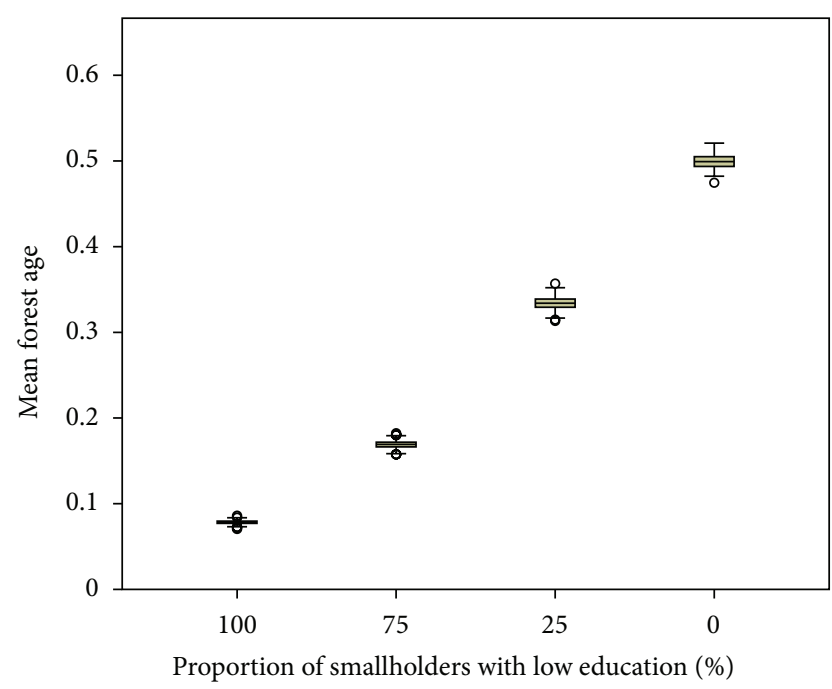

Figure 3: Mean forest age (at the landscape scale) increases significantly with a decrease in the proportion of low educated smallholders within the landscape.

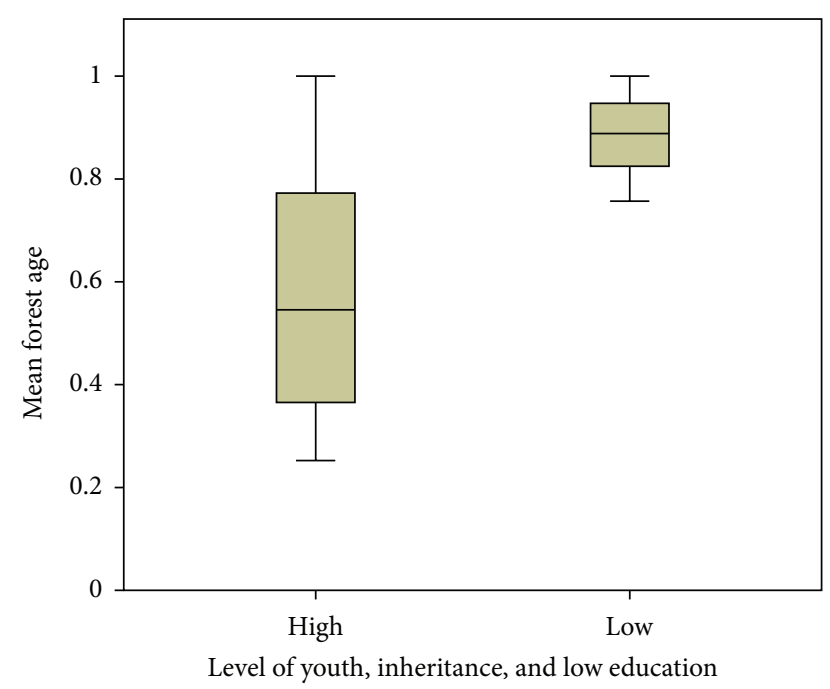

FIGURE 4: Landscapes with younger and lower educated smallholders who inherited their properties result in significantly lower average forest age at the landscape level.

introduces a new emergent phenomenon in the form of land use clustering. This increase in land use and land cover change clustering has the effect of ameliorating the more negative impacts of individual smallholder characteristics that are more likely to lead to clearcutting. In other words, greater levels of social influence lead to an overall increase in average forest age within the landscape (see Figure 7). This effect also holds true, as expected, for high levels of social influence and decreasing levels of absenteeism (see Figures 8 and 9).

Our model behaved as expected in these straightforward examples, given the probabilities of harvesting that we programmed to reflect what has been reported in previous studies and the NWOS. At a minimum, the model replicates expected land use trends using what we know

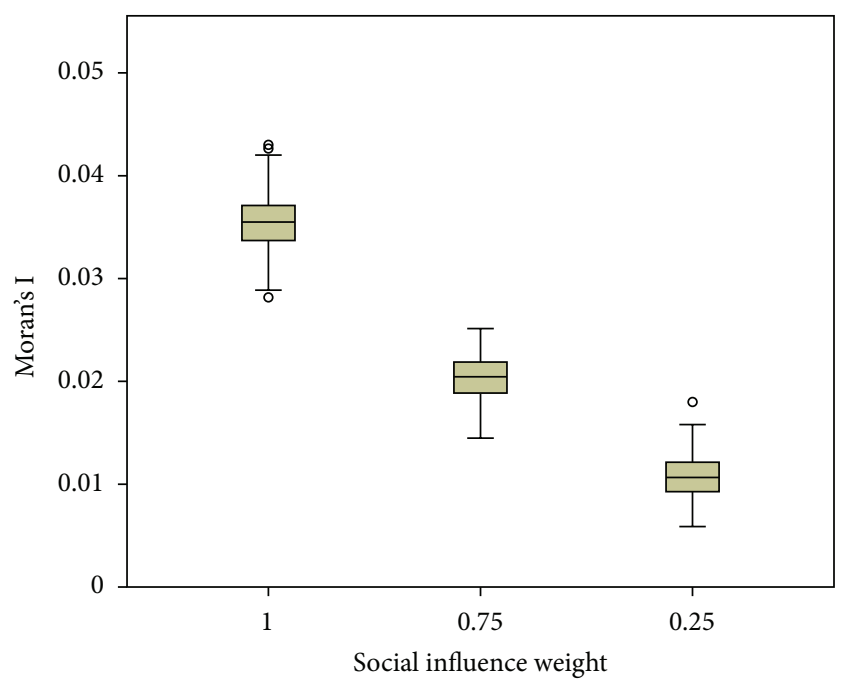

FIGURE 5: Land use and land cover change clustering (measured using Moran's I for spatial autocorrelation at the landscape scale) increases significantly with an increase in social influence.

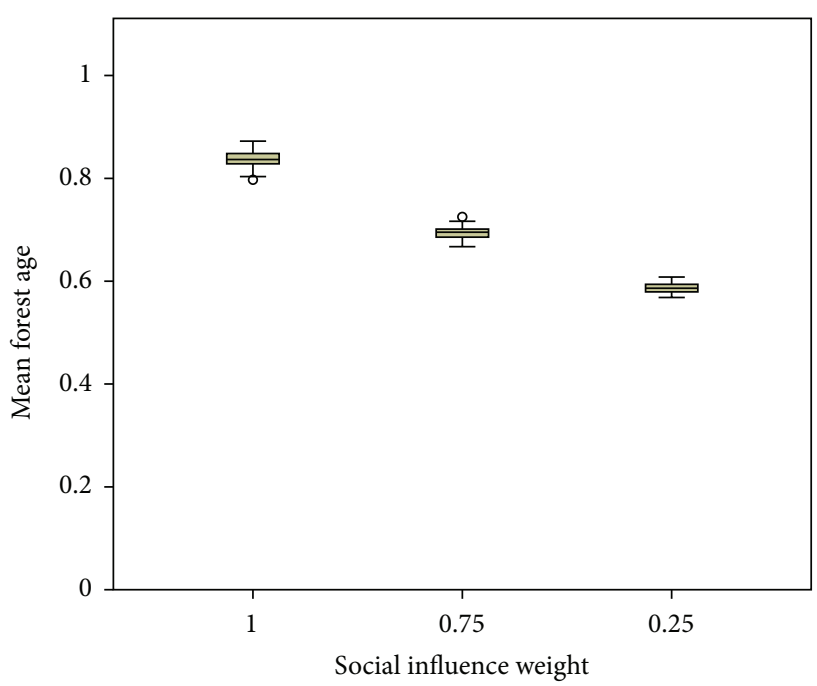

FIGURE 6: Average forest age (at the landscape scale) increases significantly with an increase in social influence despite high levels of smallholder characteristics that are likely to lead to clearcutting.

about how basic demographics impact smallholder decisionmaking. For example, we know from the literature that older smallholders are less likely to clear-cut their lands, although the reasons for this are complex; older owners typically have more wealth (and less economic need to harvest), and older owners are now more likely to be retirees from urban areas (who are less likely to harvest) than rural farmers [68]. We also know that those with a lower education are more likely to clear-cut than those with a higher education, largely due to the lack of awareness on the behalf of the less educated smallholders about the landscape consequences of individual decision-making and/or a lack of awareness of alternative land-use practices $[59,68]$. Finally, smallholders who are absentee owners (either through inheritance or 


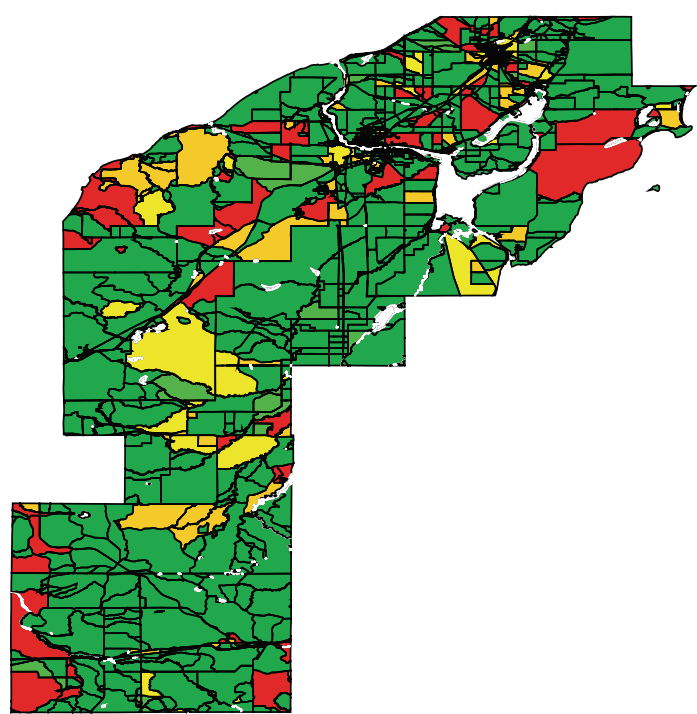

(a)

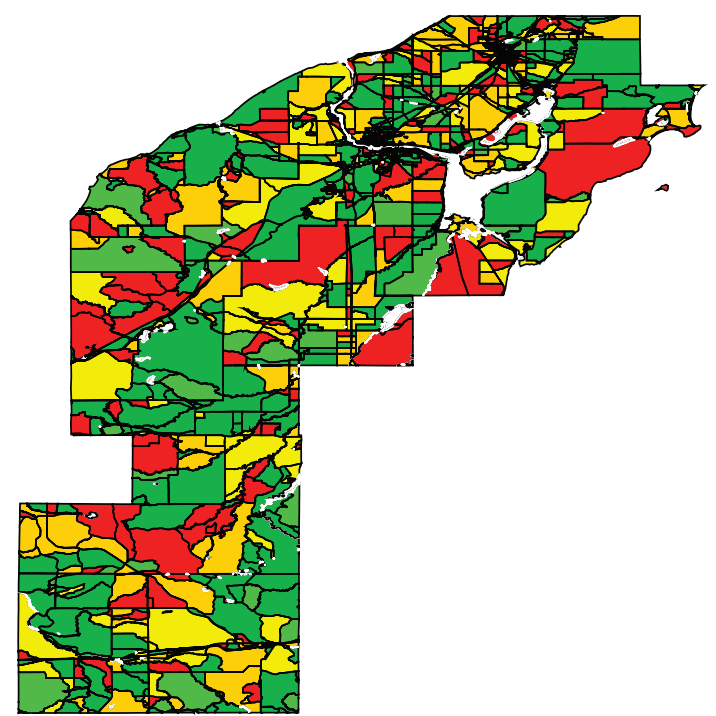

(b)

FIGURE 7: (a) is a representative map of Houghton County showing the spatial clustering and higher average forest age of simulations with high social influence. (b) is a representative map showing the lack of spatial clustering and lower average forest age of simulations with low social influence (see Figure 5 for a comparison of spatial statistics between these two maps and see Figure 6 for a comparison of average forest age). Red: clear-cut; yellow: young forest; green: old growth; white: water.

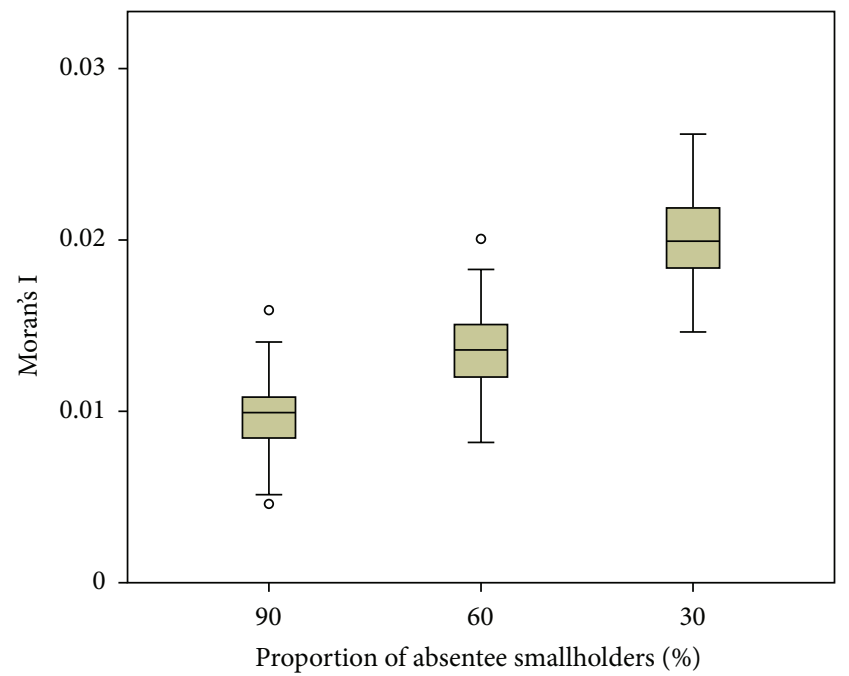

FIGURE 8: Land use and land cover change clustering (measured using Moran's I for spatial autocorrelation at the landscape scale) increases significantly with a decrease in smallholder absenteeism.

purchase) are less likely to actively manage their property, and particularly those who have purchased property tend to be older, wealthier, and more interested in the amenity value of the forest (and therefore less likely to harvest [59, 69]). The results of our model demonstrate how these basic demographic drivers impact landscape-level land use both independently and in combination with one another. We see that, taking into account only the demographic drivers, we are able to replicate expected reductions in mean forest age (for the landscape as a whole), but at present we are unable

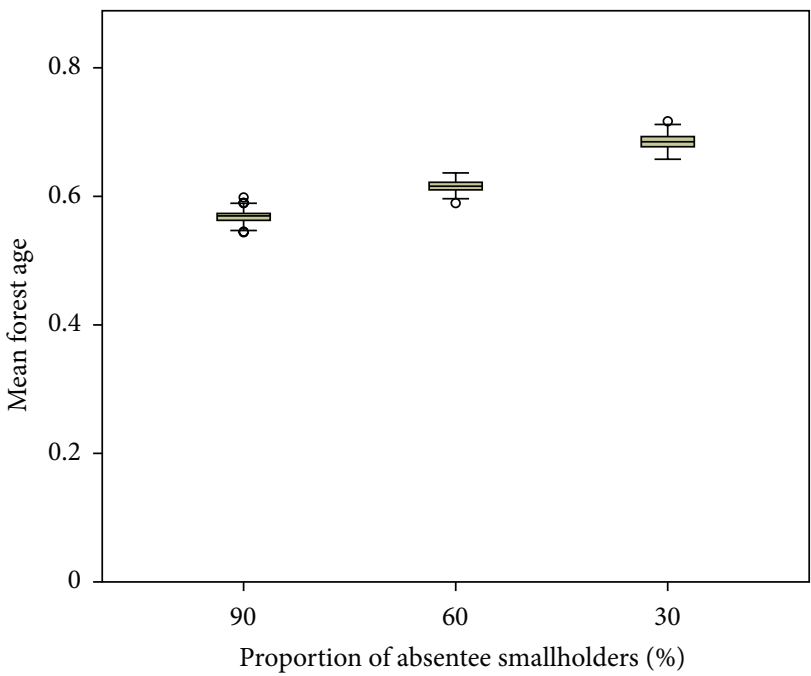

FIGURE 9: Average forest age (at the landscape scale) increases significantly with a decrease in absenteeism with high levels of social influence and high levels of smallholder characteristics that are likely to lead to clear cutting.

to replicate spatially explicit landscape features such as forest cover change clustering.

The introduction of our two "social" drivers (neighbor influence and absentee ownership) enables the model to generate the more complex landscape pattern of cover change clustering. Neighbor influence unlocks the flow of information from those who practice sustainable land-use management to those who do not but who may simply lack awareness of these sustainable alternatives. Consequently, neighbor influence results in an increase in mean forest age 
but only so long as absentee ownership does not counteract (i.e., break the social link between neighbors) this mechanism of information flow [69]. Finally, the resulting cover change clustering that emerges from neighbor influence not only is more consistent with our expectations of land use and land cover change but also highlights an important mechanism for land managers who have an interest in encouraging more sustainable land use practices in the future. For example, if a land manager used average forest stand age as an indicator for a sustainable forested landscape (reflecting old growth forest dominating the landscape in large patches), with some young forest and clear cut patches for diversity, the land manager could determine with this model the level of social influence necessary to counteract an abundance of young absentee smallholders. The land manager could try to promote social influence through incentive programs or collaboration with smallholder associations, for example. In this way, the model can be used to project the potential impact of demographic trends (smallholder age, increasing education levels) on landscapes and to prioritize the efforts of land management agencies in terms of smallholder policies. The model could also be used to identify local portions of the landscape where sustainability goals are likely to be frustrated without programmatic intervention, for example, in townships within the county with low high school graduation rates.

The GIS capability of our model allows us to visualize what these landscapes look like, so that we know not only the mean age of the forested landscape but also other characteristics as well, such as patchiness and connectivity of forests of different age classes. These landscape patterns influence many ecological processes that are of interest to smallholders, such as the risks of wildfires and pests or the dispersal of wildlife and game animals. More proximate to our interests, the landscapes demonstrate the profound impact that smallholder decision-making can have at this scale.

\section{Conclusions}

Our preliminary results indicate that the model produces reasonable and interesting outcomes from scenarios, particularly those with multiple interacting variables. As currently designed, the model generates information on mean forest age at the landscape scale, clustering (or patch size) of different forest age classes, and hence an indirect measure of forest connectivity. All three output variables are important to sustainable forest management and can influence the value of amenity and nonwood products from the forest. This model is in its preliminary stages, and a great deal of work is needed before it will be useful for researchers, landowner associations, and policy makers. Some of these issues speak to the inherent difficulties of pairing static GIS layers with dynamic agent-based models and others to the broader challenges presented by complex coupled human and environment systems. To develop the model further, we will focus on verification, property boundary dynamics, and the realism of the agents. Once we have identified realistic boundaries for these dynamics, we will then incorporate broader issues such as the influence of market forces (e.g., bioenergy, timber, and pulp prices), invasive species, and climate change, all of which will constrain certain harvesting or other land management choices that agents can make. Below, we discuss three areas for future model development necessary to extend upon what we have accomplished in this paper. Upon completing these three development stages, we believe our model will be ready to serve as a valuable simulation tool for land managers seeking to better understand the complexities of land use decision-making as well as the impacts of proposed policy changes on landscape-level sustainability.

\subsection{Verifying Harvest Rates and Patterns among Private} Landowners. We are currently working on a remote sensingbased approach to verify harvest and reforestation rates in smallholder-dominated areas, so that we can assure that our model results are reasonable. Our approach is similar to that taken by Evans and Kelley [48, 49] and Kelley and Evans [50] for verifying the reforestation rate in southern Indiana (USA) due to smallholder land management decisions, using aerial photography. Ultimately, we want to assure that our model is producing not only the harvest rates but also patterns that have been observed in the area in the recent past, so that our model can be used to produce reasonable scenarios for future harvest rates and patterns given trends in smallholder characteristics and decision-making [17, 42].

\subsection{Incorporating Parcelization. Models combining GIS with} agent-based models have been used to manage recreational opportunities in North American parks [70, 71], to understand forest owners' decision-making in response to changes in tax structures and threats from invasive species in Maine [72], and to measure the impact of fuel wood collection on giant panda habitat in China [12] and the ecological impacts of enrollment patterns in the Conservation Reserve Program for agricultural areas in Illinois [73], among other uses [74, 75]. However, given the static nature of most GIS data layers [42], incorporating parcelization when a parcel shapefile defines the agents is problematic. However, parcelization (the splitting of one property into several) is an important driver in deforestation and conversion to other land use types [76], particularly in the northern Midwestern United States [77]. The integration of GIS-based data into spatially explicit multiagent models (or object-oriented models, e.g., cellular automata, individual- or agent-based models, etc.) can be challenging, since these data are typically static due to their collection method (e.g., satellites that pass over once per month $[42,66])$. This creates difficulties with respect to the temporal dimension of dynamic models; however there are methods that allow for this difficulty to be overcome, within GIS software and agent-based modeling programs $[12,66]$.

5.3. More Realistic Agents. Land managers rarely operate completely independently but instead are influenced by other land managers and governance institutions in a variety of ways. This influence can be direct (e.g., speaking to each other about management ideas) or indirect (e.g., observing the impact of another's management decisions $[59,78])$. Additionally, owners can form associations or cooperatives 
that purposely or coincidentally coordinate management decision-making or otherwise promote conformity [79], which can facilitate meeting policy or programmatic goals if these groups are given incentives towards particular management goals $[52,80]$. We will add social network modeling methods to help elucidate these social structures [22]. Furthermore, economic influences on our modeled smallholders are implicit; in other words, we use a stochastic element to drive the aspects of harvest decision-making that are not modeled explicitly; absentee smallholders may be more likely to clear-cut because they only place a monetary value on the timber products their forest provides versus the aesthetic values that are nonzero for residents, for example. However, economics do influence smallholders and therefore land use and land cover change [48, 49, 81]. Relatively little information is available on absentee smallholders, and in some cultures or regions these smallholders may have dramatically different values for their land [68]. Our model would be more helpful to policy makers if economic and residence influences are made more explicit.

\section{Acknowledgments}

The authors would like to thank Mackenzie Roeser and Jillian Schubert for their assistance with modeling and sociological data collection, respectively. This work was partially funded by a US Department of Agriculture, Forest Service MacIntyre-Stennis Grant to Audrey L. Mayer, an Oak Ridge Associated Universities Powe award to Audrey L. Mayer, and a Research Seed Grant from Michigan Tech to Audrey L. Mayer and Mark D. Rouleau.

\section{References}

[1] J. A. Foley, R. DeFries, G. P. Asner et al., "Global consequences of land use," Science, vol. 309, no. 5734, pp. 570-574, 2005.

[2] A. L. Mayer, "Strengths and weaknesses of common sustainability indices for multidimensional systems," Environment International, vol. 34, no. 2, pp. 277-291, 2008.

[3] FAO (Food and Agriculture Organization of the United Nations), FAO Strategy for Forests and Forestry, FAO, Rome, Italy, 2013, http://www.fao.org/docrep/012/al043e/al043e00 .pdf.

[4] I. Stupak Inge, B. Lattimore, B. D. Titus, and C. Tattersall Smith, "Criteria and indicators for sustainable forest fuel production and harvesting: a review of current standards for sustainable forest management," Biomass and Bioenergy, vol. 35, no. 8, pp. 3287-3308, 2011.

[5] D. J. Krieger, The Economic Value of Forest Ecosystem Services: A Review, The Wilderness Society, Washington, DC, USA, 2001.

[6] M. J. Metzger, M. D. A. Rounsevell, L. Acosta-Michlik, R. Leemans, and D. Schröter, "The vulnerability of ecosystem services to land use change," Agriculture, Ecosystems and Environment, vol. 114, no. 1, pp. 69-85, 2006.

[7] F. Kienast, J. Bolliger, M. Potschin et al., "Assessing landscape functions with broad-scale environmental data: Insights gained from a prototype development for Europe," Environmental Management, vol. 44, no. 6, pp. 1099-1120, 2009.
[8] P. R. Ehrlich, P. M. Kareiva, and G. C. Daily, "Securing natural capital and expanding equity to rescale civilization," Nature, vol. 486, no. 7401, pp. 68-73, 2012.

[9] T. R. Crow, G. E. Host, and D. J. Mladenoff, "Ownership and ecosystem as sources of spatial heterogeneity in a forested landscape, Wisconsin, USA," Landscape Ecology, vol. 14, no. 5, pp. 449-463, 1999.

[10] R. de Groot, "Function-analysis and valuation as a tool to assess land use conflicts in planning for sustainable, multi-functional landscapes," Landscape and Urban Planning, vol. 75, no. 3-4, pp. 175-186, 2006.

[11] W. E. Odum, "Environmental degradation and the tyranny of small decisions," BioScience, vol. 32, no. 9, pp. 728-729, 1982.

[12] L. An, M. Linderman, J. Qi, A. Shortridge, and J. Liu, "Exploring complexity in a human-environment system: an agent-based spatial model for multidisciplinary and multiscale integration," Annals of the Association of American Geographers, vol. 95, no. 1, pp. 54-79, 2005.

[13] D. Valbuena, P. H. Verburg, A. K. Bregt, and A. Ligtenberg, "An agent-based approach to model land-use change at a regional scale," Landscape Ecology, vol. 25, no. 2, pp. 185-199, 2010.

[14] A. R. Cabrera, P. Deadman, E. Moran, E. S. Brondízio, and L. K. Vanway, "Exploring demographic and lot effects in an ABM/LUCC of agriculture in the Brazilian Amazon," in AgentBased Models of Geographic Systems, A. J. Heppenstall, A. T. Crooks, L. M. See, and M. Batty, Eds., pp. 663-676, Springer, New York, NY, USA, 2012.

[15] Z. Ma, B. J. Butler, D. B. Kittredge, and P. Catanzaro, "Factors associated with landowner involvement in forest conservation programs in the U.S.: implications for policy design and outreach," Land Use Policy, vol. 29, pp. 53-61, 2012.

[16] A. L. Mayer and P. M. Tikka, "Biodiversity conservation incentive programs for privately owned forests," Environmental Science and Policy, vol. 9, no. 7-8, pp. 614-625, 2006.

[17] D. C. Parker, S. M. Manson, M. A. Janssen, M. J. Hoffmann, and P. Deadman, "Multi-agent systems for the simulation of landuse and land-cover change: a review," Annals of the Association of American Geographers, vol. 93, no. 2, pp. 314-337, 2003.

[18] E. F. Lambin and P. Meyfroidt, "Global land use change, economic globalization, and the looming land scarcity," Proceedings of the National Academy of Sciences of the United States of America, vol. 108, no. 9, pp. 3465-3472, 2011.

[19] F. Bousquet and C. Le Page, "Multi-agent simulations and ecosystem management: a review," Ecological Modelling, vol. 176, no. 3-4, pp. 313-332, 2004.

[20] V. Grimm, E. Revilla, U. Berger et al., "Pattern-oriented modeling of agent-based complex systems: lessons from ecology," Science, vol. 310, no. 5750, pp. 987-991, 2005.

[21] L. An, "Modeling human decisions in coupled human and natural systems: review of agent-based models," Ecological Modelling, vol. 299, pp. 25-36, 2012.

[22] M. Schlüter, R. R. J. Mcallister, R. Arlinghaus et al., "New horizons for managing the environment: a review of coupled social-ecological systems," Natural Resource Modeling, vol. 25, no. 1, pp. 219-272, 2012.

[23] J. P. Baker, D. W. Hulse, S. V. Gregory et al., "Alternative futures for the Willamette River Basin, Oregon," Ecological Applications, vol. 14, no. 2, pp. 313-324, 2004.

[24] M. D. A. Rounsevell, I. Reginster, M. B. Araújo et al., "A coherent set of future land use change scenarios for Europe," Agriculture, Ecosystems and Environment, vol. 114, no. 1, pp. 57-68, 2006. 
[25] A. Pocewicz, M. Nielsen-Pincus, C. S. Goldberg et al., "Predicting land use change: comparison of models based on landowner surveys and historical land cover trends," Landscape Ecology, vol. 23, no. 2, pp. 195-210, 2008.

[26] M. L. Zellner, T. L. Theis, A. T. Karunanithi, A. S. Garmestani, and H. Cabezas, "A new framework for urban sustainability assessments: linking complexity, information and policy," Computers, Environment and Urban Systems, vol. 32, no. 6, pp. 474488, 2008.

[27] B. A. Bryan, N. D. Crossman, D. King, and W. S. Meyer, "Landscape futures analysis: assessing the impacts of environmental targets under alternative spatial policy options and future scenarios," Environmental Modelling and Software, vol. 26, no. 1, pp. 83-91, 2011.

[28] L. Parrott, C. Chion, R. Gonzalés, and G. Latombe, "Agents, individuals, and networks: modeling methods to inform natural resource management in regional landscapes," Ecology and Society, vol. 17, no. 3, article 32, 170332 pages, 2012.

[29] P. A. Soranno, S. L. Hubler, S. R. Carpenter, and R. C. Lathrop, "Phosphorus loads to surface waters: a simple model to account for spatial pattern of land use," Ecological Applications, vol. 6, no. 3, pp. 865-878, 1996.

[30] S. Carpenter, W. Brock, and P. Hanson, "Ecological and social dynamics in simple models of ecosystem management," Conservation Ecology, vol. 3, no. 2, article 4, 1999.

[31] V. Christensen and C. J. Walters, "Ecopath with ecosim: methods, capabilities and limitations," Ecological Modelling, vol. 172, no. 2-4, pp. 109-139, 2004.

[32] A. L. Mayer and M. Rietkerk, "The dynamic regime concept for ecosystem management and restoration," BioScience, vol. 54, no. 11, pp. 1013-1020, 2004.

[33] H. W. Whitmore, C. W. Pawlowski, H. Cabezas, A. L. Mayer, and N. T. Hoagland, "Integration of an economy under imperfect competition with a twelve-cell ecological model," U.S. Environmental Protection Agency, Office of Research and Development, EPA/600/R-06/046, 2006.

[34] J. Hartter and K. Boston, "An integrated approach to modeling resource utilization for rural communities in developing countries," Journal of Environmental Management, vol. 85, no. 1, pp. 78-92, 2007.

[35] D. G. Brown, B. C. Pijanowski, and J. D. Duh, "Modeling the relationships between land use and land cover on private lands in the Upper Midwest, USA," Journal of Environmental Management, vol. 59, no. 4, pp. 247-263, 2000.

[36] S. M. Pearson, M. G. Turner, and J. B. Drake, "Landscape change and habitat availability in the Southern Appalachian Highlands and Olympic Peninsula," Ecological Applications, vol. 9, no. 4, pp. 1288-1304, 1999.

[37] D. J. Mladenoff, "LANDIS and forest landscape models," Ecological Modelling, vol. 180, no. 1, pp. 7-19, 2004.

[38] N. H. Schumaker, T. Ernst, D. White, J. Baker, and P. Haggerty, "Projecting wildlife responses to alternative future landscapes in Oregon's Willamette Basin," Ecological Applications, vol. 14, no. 2, pp. 381-400, 2004.

[39] K. N. Johnson, P. Bettinger, J. D. Kline et al., "Simulating forest structure, timber production, and socioeconomic effects in a multi-owner province," Ecological Applications, vol. 17, no. 1, pp. 34-47, 2007.

[40] J. H. Miller and S. E. Page, Complex Adaptive Systems: An Introduction to Computational Models of Social Life, Princeton University Press, Princeton, NJ, USA, 2007.
[41] D. L. DeAngelis and L. J. Gross, Eds., Individual-Based Models and Approaches in Ecology, Chapman and Hall, New York, NY, USA, 1992.

[42] H. R. Gimblett, "Integrating geographic information systems and agent-based technologies for modeling and simulating social and ecological phenomena," in Integrating Geographic Information Systems and Agent-Based Modeling Techniques for Simulating Social and Ecological Processes, H. R. Gimblett, Ed., pp. 1-20, Santa Fe Institute Studies in the Sciences of Complexity, Oxford University Press, Oxford, UK, 2002.

[43] M. Batty, "A generic framework for computational spatial modeling," in Agent-Based Models of Geographical Systems, A. J. Heppenstall, A. T. Crooks, L. M. See, and M. Batty, Eds., pp. 19-50, Springer, New York, NY, USA, 2012.

[44] M. F. Hill and H. Caswell, "Habitat fragmentation and extinction thresholds on fractal landscapes," Ecology Letters, vol. 2, no. 2, pp. 121-127, 1999.

[45] M. Huston, D. DeAngelis, and W. Post, "New computer models unify ecological theory," BioScience, vol. 38, no. 10, pp. 682-691, 1988.

[46] S. M. Duke-Sylvester and L. J. Gross, "Integrating spatial data into an agent-based modeling system: ideas and lessons from the development of the across-trophic-level-systemsimulation," in Integrating Geographic Information Systems and Agent-Based Modeling Techniques for Simulating Social and Ecological Processes, H. R. Gimblett, Ed., pp. 125-136, Santa Fe Institute Studies in the Sciences of Complexity, Oxford University Press, Oxford, UK, 2002.

[47] P. Deadman, D. Robinson, E. Moran, and E. Brondizio, "Colonist household decisionmaking and land-use change in the Amazon Rainforest: an agent-based simulation," Environment and Planning B, vol. 31, no. 5, pp. 693-709, 2004.

[48] T. P. Evans and H. Kelley, "Multi-scale analysis of a household level agent-based model of landcover change," Journal of Environmental Management, vol. 72, no. 1-2, pp. 57-72, 2004.

[49] T. P. Evans and H. Kelley, "Assessing the transition from deforestation to forest regrowth with an agent-based model of land cover change for south-central Indiana (USA)," Geoforum, vol. 39, no. 2, pp. 819-832, 2008.

[50] H. Kelley and T. Evans, "The relative influences of land-owner and landscape heterogeneity in an agent-based model of landuse," Ecological Economics, vol. 70, no. 6, pp. 1075-1087, 2011.

[51] C. Simon and M. Etienne, "A companion modelling approach applied to forest management planning," Environmental Modelling and Software, vol. 25, no. 11, pp. 1371-1384, 2010.

[52] M. D. Rounsevell, D. T. Robinson, and D. Murray-Rust, "From actors to agents in socio-ecological systems models," Philosophical Transactions of the Royal Society of London B, vol. 367, no. 1586, pp. 259-269, 2012.

[53] Michigan Natural Features Inventory, Biotics Database, 2012.

[54] Houghton County Michigan, Land Use Plan (County Development Plan), 2006, http://www.houghtoncounty.net/docs/ LandUsePlanText.pdf.

[55] C. A. Miller, R. E. Froese, and L. A. Leefers, Consequences of Corporate Timberland Ownership Change in Michigan's Upper Peninsula, Land Policy Institute, Michigan State University, 2007.

[56] A. L. Haines and D. McFarlane, "Factors influencing parcelization in amenity-rich rural areas," Journal of Planning Education and Research, vol. 32, no. 1, pp. 81-90, 2012. 
[57] D. G. Brown, "Land use and forest cover on private parcels in the Upper Midwest USA, 1970 to 1990," Landscape Ecology, vol. 18, no. 8, pp. 777-790, 2003.

[58] B. J. Butler, E. C. Leatherberry, and M. S. Williams, Design, Implementation, and Analysis Methods for the National Woodland Owner Survey, US Department of Agriculture Forest Service, Northern Research Station GT, Amherst, Mass, USA, 2005.

[59] J. R. Schubert and A. L. Mayer, "Peer influence of nonindustrial private forest owners in the Western Upper Peninsula of Michigan," Open Journal of Forestry, vol. 2, no. 3, pp. 147-155, 2012.

[60] M. Niazi and A. Hussain A, "Agent-based computing from multi-agent systems to agent-based models: a visual survey," Scientometrics, vol. 89, no. 2, pp. 479-499, 2011.

[61] R. Axtell, "Why agents: on the varied motivations for agent computing in the social sciences," Brooking Institution Working Paper, no. 17, 2000.

[62] H. van Dyke Parunak, R. Savit, and R. L. Riolo, "Agent-based modeling versus equation-based modeling: a case study and users' guide," in Proceedings of the Workshop on MultiagentBased Simulation, vol. 1534 of Lecture Notes in Computer Science, pp. 10-25, Springer, New York, NY, USA, 1998.

[63] J. M. Epstein and R. Axtell, Growing Artificial Societies: Social Science From the Bottom-Up, Brookings Institution Press, 1996.

[64] V. Grimm, U. Berger, D. L. DeAngelis, J. G. Polhill, J. Giske, and S. F. Railsback, "The ODD protocol: a review and first update," Ecological Modelling, vol. 221, no. 23, pp. 2760-2768, 2010.

[65] S. Luke, C. Cioffi-Revilla, L. Panait, K. Sullivan, and G. Balan, "MASON: a multiagent simulation environment," Simulation, vol. 81, no. 7, pp. 517-527, 2005.

[66] A. T. Crooks and C. J. E. Castle, "The integration of agentbased modelling and geographical information for geospatial simulation," in Agent-Based Models of Geographic Systems, A. J. Heppenstall, A. T. Crooks, L. M. See, and M. Batty, Eds., pp. 219-251, Springer, New York, NY, USA, 2012.

[67] A. Arora-Jonsson, Gender, Development and Environmental Governance: Theorizing Connections, Routledge, New York, NY, USA, 2013.

[68] B. J. Butler and Z. Ma, "Family forest owner trends in the Northern United States," Northern Journal of Applied Forestry, vol. 28, no. 1, pp. 13-18, 2011.

[69] P. Petrzelka, Z. Ma, and S. Malin, "The elephant in the room: absentee landowner issues in conservation and land management," Land Use Policy, vol. 30, pp. 157-166, 2013.

[70] H. R. Gimblett, M. T. Richards, and R. M. Itami, "Simulating wildland recreation use and conflicting spatial interactions using rule-driven intelligent agents," in Integrating Geographic Information Systems and Agent-Based Modeling Techniques for Simulating Social and Ecological Processes, H. R. Gimblett, Ed., pp. 211-244, Santa Fe Institute Studies in the Sciences of Complexity, Oxford University Press, Oxford, UK, 2002.

[71] H. R. Gimblett, C. A. Roberts, T. C. Daniel et al., "An intelligent agent-based model for simulating and evaluating river trip scenarios along the Colorado River in Grand Canyon National Park," in Integrating Geographic Information Systems and AgentBased Modeling Techniques for Simulating Social and Ecological Processes, H. R. Gimblett, Ed., pp. 245-276, Santa Fe Institute Studies in the Sciences of Complexity, Oxford University Press, Oxford, UK, 2002.

[72] J. E. Leahy, E. L. Gorczyca, K. P. Bell, C. L. Straub, and J. S. Wilson, "Agent-based modeling of harvest decisions by small scale forest landowners in Maine, USA," International Journal of Forestry Research. In press.

[73] R. Sengupta, C. Lant, S. Kraft, J. Beaulieu, W. Peterson, and T. Loftus, "Modeling enrollment in the conservation reserve program by using agents within spatial decision support systems: an example from southern Illinois," Environment and Planning $B$, vol. 32, no. 6, pp. 821-834, 2005.

[74] D. G. Brown, R. Riolo, D. T. Robinson, M. North, and W. Rand, "Spatial process and data models: toward integration of agentbased models and GIS," Journal of Geographical Systems, vol. 7, no. 1, pp. 25-47, 2005.

[75] A. J. Heppenstall, A. T. Crooks, L. M. See, and M. Batty, Eds., Agent-Based Models of Geographical Systems, Springer, New York, NY, USA, 2012.

[76] E. J. Gustafson and C. Loehle, "Effects of parcelization and land divestiture on forest sustainability in simulated forest landscapes," Forest Ecology and Management, vol. 236, no. 2-3, pp. 305-314, 2006.

[77] A. L. Haines, T. T. Kennedy, and D. L. McFarlane, "Parcelization: forest change agent in Northern Wisconsin," Journal of Forestry, vol. 109, no. 2, pp. 101-108, 2011.

[78] R. J. Gass, M. Rickenbach, L. A. Schulte, and K. Zeuli, “Crossboundary coordination on forested landscapes: investigating alternatives for implementation," Environmental Management, vol. 43, no. 1, pp. 107-117, 2009.

[79] W. G. Kennedy, "Modelling human behavior in agent-based models," in Agent-Based Models of Geographic Systems, A. J. Heppenstall, A. T. Crooks, L. M. See, and M. Batty, Eds., pp. 167-179, Springer, New York, NY, USA, 2012.

[80] P. van Gossum, S. Luyssaert, I. Serbruyns, and F. Mortier, “Forest groups as support to private forest owners in developing closeto-nature management," Forest Policy and Economics, vol. 7, no. 4, pp. 589-601, 2005.

[81] E. G. Irwin and J. Geoghegan, "Theory, data, methods: developing spatially explicit economic models of land use change," Agriculture, Ecosystems and Environment, vol. 85, no. 1-3, pp. 7-23, 2001 

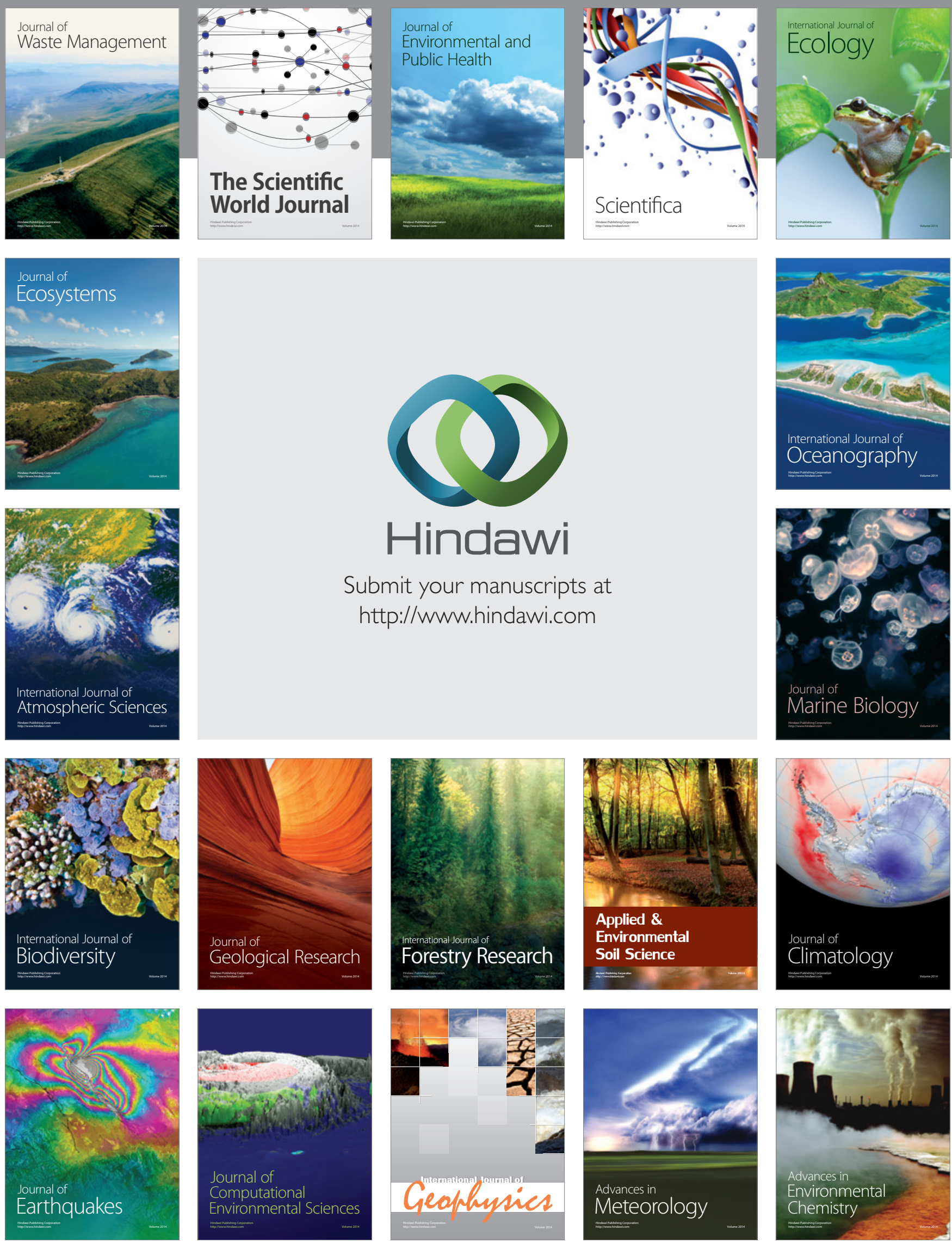